\title{
Tipos de conhecimento regional protegidos pelas instituições na indicação de procedência Canastra (MG)
}

\author{
Types of regional knowledge protected by institutions under the Canastra \\ designation of origin (MG)
}

\author{
Ligia Aparecida Inhan Matos ${ }^{1}$ (D), Renata Lèbre La Rovere ${ }^{2}$ (D) \\ ${ }^{1}$ Editora Sociedade Espírita Primavera, Setor Administrativo, Juiz de Fora (MG), Brasil. E-mail: ligia.inhan@gmail.com \\ ${ }^{2}$ Instituto de Economia, Programa de Pós-graduação Políticas Públicas, Estratégias e Desenvovlimento, Universidade Federal \\ do Rio de Janeiro (UFRJ), Rio de Janeiro (RJ), Brasil. E-mail: renata@ie.ufrj.br
}

Como citar: Matos, L. A. I., \& La Rovere, R. L. (2020). Tipos de conhecimento regional protegidos pelas instituições na indicação de procedência Canastra (MG). Revista de Economia e Sociologia Rural, 58(2), e188623. https://doi.org/10.1590/1806-9479.2020.188623

\begin{abstract}
Resumo: Este artigo tem o objetivo de demonstrar quais são os tipos de conhecimento na região coberta pela Indicação de Procedência Canastra (IP) após a inserção do conhecimento da legislação sanitária e da Indicação Geográfica (IG). Como objetivo específico, busca entender como as relações de confiança entre instituições na região foram afetadas pela Gl. A metodologia utilizada foi qualitativa, envolvendo pesquisa documental e entrevistas. A técnica de análise dos dados foi análise de conteúdo, com o auxílio do software Atlas TI. A pesquisa de campo levantou os conceitos-chave a partir da perspectiva dos produtores e das instituições endógenas e exógenas. Como principais resultados, destacam-se: partes do conhecimento da legislação foram incorporadas ao processo produtivo do Queijo Minas Artesanal (QMA) por meio do Dossiê interpretativo do Instituto do Patrimônio Histórico e Artístico Nacional (IPHAN) e do Regulamento de Uso (RU) da IP. Este conhecimento tem sido disseminado notadamente pelo Instituto Mineiro de Agropecuária (IMA) e pelo Ministério da Agricultura, Pecuária e Abastecimento (MAPA). O conhecimento da IG tem sido disseminado principalmente entre os produtores pela Associação dos Produtores do Queijo Canastra (APROCAN). Conclui-se que os três tipos de conhecimento encontrados - protegido, exógeno e tácito - sofreram importante influência pela inserção da legislação e pouca influência do conhecimento da IG. O conhecimento da legislação alterou as relações de confiança entre as instituições endógenas e exógenas.
\end{abstract}

Palavras-chave: indicação geográfica, IP da Canastra, conhecimento regional, instituições.

Abstract: This work aims to discuss the types of knowledge in the region under the Canastra designation of origin (DO) after the insertion of knowledge of health legislation and of geographical indication (GI). As a specific objective, it seeks to understand how the relations of trust among institutions in the region have been affected by GI. The qualitative research method of this work involved content analysis of documents and interviews with the help of the software Atlas.Ti. The main results are: parts of the knowledge of the legislation were incorporated into the production process of the Artisanal Cheese Minas Artisanal through the Interpretative Dossier of the Brazilian National Historical and Artistic Heritage Institute and the Regulation of Use of IO. This knowledge has been widely disseminated by the Minas Gerais Institute of Agriculture and the Ministry of Agriculture, Livestock and Supply The knowledge of $\mathrm{Gl}$ has been disseminated mainly among the producers by the Canastra Cheese Producers Association. It is possible to conclude that the three types of knowledge found; protected, exogenous and tacit, have been strongly influenced by the insertion of the legislation and weakly influenced by knowledge of the Gl. Knowledge of legislation has altered the relationship of trust between endogenous and exogenous institutions.

Keywords: geographic indication, Canastra DO, regional knowledge, institutions. 


\section{INTRODUÇÃO}

A região da Serra da Canastra é conhecida pela fabricação do Queijo Minas Artesanal (QMA) e, como outras regiões do Estado e do país, apresenta uma forte relação da produção com a cultura regional, juntamente com a diversificação de produtos e a atividade leiteira. Toda a região da Canastra é relevante socioeconomicamente para a agricultura familiar (Cintrão, 2016; Simoncini, 2017).

Inúmeras modificações legislativas e regulamentares ocorreram desde o início dos anos 2000, realizadas por instituições endógenas e exógenas, em consequência da adesão do Brasil ao Mercado Comum do Sul (MERCOSUL) (Matos, 2016; Shiki \& Wilkinson, 2016).

Uma das intervenções foi a demarcação de territórios dentro de uma ampla zona de produção do QMA no estado de Minas Gerais. Essas demarcações serviram tanto para reconhecimento formal pelo Instituto Mineiro de Agropecuária (IMA) quanto para o registro de duas regiões, Serro e Canastra, cada uma com Indicação de Procedência (IP) do Instituto Nacional de Propriedade Intelectual (INPI).

A Lei n. ${ }^{\circ}$ 9.279, de 14 de maio de 1996, criou um capítulo específico para as Indicações Geográficas (IG) e teve a função de implementar a adesão à Organização Mundial do Comércio (OMC) e o Acordo dos Direitos da Propriedade Intelectual Relacionados ao Comércio (ADIPC/TRIPS). Esse mecanismo legal de propriedade intelectual tem como objetivo assegurar o conhecimento regional em regiões tradicionais brasileiras ${ }^{1}$. O Brasil definiu dois tipos de sinais distintivos, a IP e a Denominação de Origem (DO) (Cerdan et al., 2014; Valente et al., 2013).

Num sentido amplo, uma IG é um tipo de registro de proteção do conhecimento em que se reconhece um vínculo específico entre um produto ou serviço e seu território. As especificidades de solo, clima, história e saber fazer são elementos marcantes percebidos como valor qualitativo nos produtos e que são reconhecidos como um terroir distinto, implicando uma tradição produtiva forte como principal gerador de valor e veículo do conhecimento (Cerdan et al., 2014; Niederle et al., 2016; Ribeiro \& Santos, 2008).

No entanto, as rotinas da legislação sanitária e da implantação da IP são conhecimentos novos, introduzidos por instituições exógenas à região. Surge a necessidade de melhor organizar os produtores para que as informações novas difundidas atinjam a todos os produtores da região, incluindo os mais descapitalizados, evitando que sejam prejudicados no acesso a novos mercados possibilitados pela IG. Esse é um dos maiores desafios na implementação das IGs (Mafra, 2010).

Assim, é interessante entender como esses conhecimentos foram disseminados na região e se eles tiveram alguma influência nas relações de confiança entre produtores e instituições.

Este artigo tem por objetivo demonstrar os tipos de conhecimento que circulam na Indicação de Procedência Canastra a partir da entrada das rotinas da legislação sanitária no processo produtivo artesanal e da estruturação da IP. Como objetivo específico, buscou-se verificar se o conhecimento novo trazido pelas instituições exógenas afetou as relações de confiança entre os produtores e as instituições endógenas e exógenas. Para atingir esses objetivos, foi desenvolvida uma metodologia de pesquisa qualitativa, com análise de conteúdo de documentos e de entrevistas, com o auxílio do software Atlas TI. O artigo contribui para a discussão acadêmica no campo do desenvolvimento regional, buscando levantar os conflitos de introdução de novos conhecimentos de legislação industrial sanitária e sistemas produtivos artesanais, especialmente do queijo, em regiões protegidas por direitos de propriedade intelectual.

Este artigo é dividido nas seguintes seções: a seção 2 apresenta uma discussão sobre a origem das instituições e a formação da tradição produtiva, originária do terroir; a seção 3 fala sobre o contexto da IP da Canastra, no qual diversas instituições foram demandadas a fim de proteger o Queijo Minas Artesanal, ameaçado de extinção pela adesão do Brasil ao Mercosul; a seção 4 apresenta os procedimentos metodológicos e a codificação dos documentos levantados na pesquisa de campo; a seção 5 apresenta a análise de conteúdo dos efeitos da

\footnotetext{
${ }^{1}$ Para um histórico sobre as leis e os decretos de proteção legal de propriedade intelectual, consulte: Matos (2016).
} 
legislação sobre o conhecimento, bem como a análise entre o registro da IP e as instituições endógenas e exógenas; por fim, a última seção avalia os resultados encontrados.

\section{O CONHECIMENTO E A TRADIÇÃO DEMARCAM UMA REGIÃO}

O conhecimento da região não se constrói somente por meio dos produtores. As diversas instituições que ali atuam, bem como os consumidores, também contribuem para a sua definição, de acordo com os estudos que versam sobre o papel do conhecimento no território, tais como Cooke et al. (2007), Britto (2004), Capello, (2013), Erber, (2008), Diniz (2013), Gonçalves et al. (2011), Matos et al. (2015), entre outros.

Nestes estudos, a aprendizagem regional foi identificada como um lugar em que processos cognitivos desempenham um papel essencial, combinando conhecimento tácito existente e disperso, necessidade de interpretação de mercado e fluxos de informação aliados ao ferramental intelectual, tais como as teorias e os modelos, a fim de permitir a troca de experiências e a cooperação (Cooke et al., 2007).

Mas o conhecimento não circula livremente entre firmas, ele é resultante de específicos caminhos de aprendizado, podendo variar conforme as especificidades do território, do produto e das características de absorção do conhecimento externo, e as relações entre instituições (Ruffoni et al., 2017).

Portanto, a cooperação depende da confiança e existem níveis de confiança que vão desde a simples obrigação de trocar conhecimento até a confiança irrestrita, o respeito pela hierarquia e o compromisso pelo compartilhamento, como afirma Polanyi (2010).

Em um nível macrossocial, o arranjo institucional que perdura por muitas décadas, até mesmo séculos, possibilita a manutenção de determinados tipos de conhecimento de processos produtivos, criando uma tradição produtiva, sem necessidade de codificação por meios de interação formais. Tais arranjos locais são encontrados notadamente em regiões produtivas agrícolas tradicionais, como em diversos países da União Europeia, por exemplo, que sustentam esse conhecimento graças a essa percepção que valoriza o produto (Pesqueux, 2010).

Em um nível microssocial, seguir uma tradição do conhecimento implica que tanto o mestre quanto o aprendiz devem ter uma postura ativa de confiança mútua, sem restrições, porque enquanto o primeiro estimula o desenvolvimento do aprendiz e o avalia criticamente, o outro aprende de forma copiando suas rotinas, a partir de uma crença justificada. Tal comportamento leva muitos anos para ser consolidado entre indivíduos (Nelson \& Winter, 2012; Polanyi, 2010).

Neste sentido, Berger \& Luckmann (2014) identificam uma sequência lógica do comportamento humano e distinguem o hábito, a rotina e a tradição, definindo-os: hábitos são ações sequenciais anteriores à criação de rotinas que, por sua vez, tornam-se uma tradição, caso úteis. A tradição surge quando as rotinas não necessitam ser justificadas, passando para a história da instituição. Esses autores afirmam que é a partir dessa partilha que as instituições, formais e informais, são criadas, sustentadas e até destruídas.

Dessa forma, a identificação de uma região produtora tradicional se revela com a história, com o modo de produção, com os hábitos peculiares do gosto, com o conhecimento do solo, do gado e da temperatura ideal, e outros tantos fatores e processos que criam o chamado terroir.

Para uma definição mais exata do que pode ser entendido por terroir, o Institut national de l'origine et de la qualité (INAO), instituição francesa de proteção à propriedade intelectual, sintetizou o conceito da seguinte forma:

Um terroir é um espaço geográfico delimitado, dentro daquela comunidade humana construída, ao curso de sua história, um saber coletivo de produção, fundado sobre um sistema de interações entre um local psíquico e biológico, e um conjunto de fatores humanos. Os caminhos sócio técnicos assim postos revelam uma originalidade, conferindo uma tipicidade, e conduzem a uma notoriedade para um bem originário deste espaço geográfico. (Institut National de L'origine et de la Qualité, 2015, p. 27, tradução nossa). 
Mas, como ressalta Laurence Bérard: “o vinho é fabricado uma vez por ano, há pouca diversidade, já o queijo é fabricado todo dia, então existe uma variação muito grande no ambiente" (BÉRARD apud Matos, 2016, p. 122). Há elementos distintivos que são partilhados diariamente entre aqueles que o produzem.

Ao olhar externo das instituições, parece um conjunto de rotinas iguais, mas, para os produtores, é um grupo complexo de conhecimentos aprendidos e apreendidos todos os dias a partir da instabilidade e diversidade do ambiente. Há, pois, características intrínsecas ao modo de produção do queijo artesanal que são exclusivas e the fornecem toda a sua unicidade (Matos, 2016).

Assim, enquanto algumas inovações que estão ocorrendo na região da Canastra são provocadas exogenamente devido à introdução da legislação sanitária e da própria IG, hábitos vão sendo criados, os quais se inserem nas novas rotinas do modo de produção. Tais mudanças de comportamento são possíveis devido às instituições locais que possuem laços de confiança estabelecidos entre os agentes ao longo do tempo e que possuem relações com outras instituições externas à região (Ruffoni et al., 2017).

Considerando instituições formais como aquelas que produzem documentos oficiais, como regulamentos e leis, e possuem meios de assegurar sua aplicação (Hodgson, 2014), às questões que se colocam e que este artigo pretende responder são:

1) Como as instituições formais têm afetado o conhecimento regional no processo de proteção do conhecimento?

2) Quais são os tipos de conhecimento que estão sendo efetivamente protegidos pelos certificados dos institutos de proteção intelectual e bens imateriais?

\section{CONTEXTUALIZAÇÃO DO CASO ANALISADO}

O Brasil aderiu ao MERCOSUL e o Ministério da Agricultura, Pecuária e Abastecimento $(\mathrm{MAPA})^{2}$ reestruturou toda a legislação da produção industrial de queijo do país. Dessa forma, criou o conceito de queijo Minas Frescal para todos os tipos de Queijo Minas pelo Decreto N. ${ }^{\circ}$ 2.244, de 4 de junho de 1997. Também estabeleceu que a maturação dos queijos de leite cru deveria ser feita por um período mínimo de 60 dias, sem fazer distinção do tipo de produção, se industrial ou artesanal (Mercosul, 1996).

A obrigação da maturação por esse longo período colocou a maioria dos produtores de queijo artesanal do Brasil na ilegalidade. Em Minas Gerais, 93\% do queijo de leite cru é vendido fresco, com até 10 dias de maturação (Cintrão, 2016; Perez, 2014; Simoncini, 2017).

A partir de então, a fiscalização e a punição - com apreensão de mercadorias e contaminação dos queijos com creolina de forma a inutilizá-los para consumo - se tornaram corriqueiras nas regiões produtoras, conforme conta uma das produtoras:

[...] Se não é para vender, não vende, mas não quero porcaria no queijo! não deixo! Só se eles me algemar! Deixa eles aqui e eu vou comer eles. Pelo amor de Deus, eu dou pros gatos, dou pros cachorros, trato para as galinhas, mas agora por creolina para nem os bichos comerem?!? Gente desde quando eu nasci, eu como queijo, eu aprendi a segurar primeiro foi um pedacinho de queijo na mão, porque não tinha bolacha, não tinha essas coisas que os meninos comem hoje em dia não. Ela [a mãe] tinha um pedacinho de queijo e dava para os meninos, tava nascendo dente, dava um durinho, para roer para coçar os dentes. Agora fazer porcaria no meu, não deixo não! (Matos, 2016, p. 142).

Alguns técnicos da EMATER relataram que a fiscalização teve início no fim do século XX, estimulada por uma denúncia do Ministério Público de Minas Gerais. Este órgão ameaçou proibir o comércio do queijo de leite cru no Mercado Central de Belo Horizonte, tradicional local de escoamento da maior parte dos queijos mineiros artesanais. A falta de uma política

\footnotetext{
${ }^{2}$ O MAPA realiza auditorias periódicas em todo o território brasileiro. O estado de Minas Gerais aderiu ao Sistema Brasileiro de Inspeção de Produtos de Origem Animal (SISBI-POA), em 2006, transferindo a fiscalização para o Estado (Cintrão, 2016).
} 
pública que voltasse a atenção para os produtores de queijo de leite cru colocou os produtores à margem do processo de industrialização, provocando a queda na qualidade em função do aumento da quantidade (Cintrão, 2016; Matos, 2016).

Após esse acontecimento, o estado de Minas Gerais - em conjunto com produtores, políticos, EMATER, IMA e a Coordenação de Incentivo à Indicação Geográfica de Produtos Agropecuários do MAPA (CIG/MAPA) ${ }^{3}$, IPHAN, INPI - iniciou o processo de proteção e, ao mesmo tempo, de intervenção no conhecimento regional e tradicional do processo produtivo do QMA.

Assim, o governo mineiro visualizou o problema da falta de tecnologia adequada à produção artesanal e buscou estabelecer parâmetros possíveis de serem alcançados. Foi também constatado que o queijo mineiro precisaria ser diferenciado do queijo Minas incluído no regulamento do MERCOSUL, pois os processos eram diferentes, embora pudessem ter tido a mesma origem (Matos, 2016).

Foi feito um convênio com o governo francês para capacitação e organização dos produtores mineiros, que fundaram a Associação dos Produtores de Queijo Canastra (APROCAN), criada especificamente para gerir a IP. A Associação para Gestão de Projetos de Fortalecimento das Economias Rurais e Desenvolvimento Territorial (AGRIFERT), uma organização não governamental francesa, impulsionou a demarcação do território da Canastra. Com o apoio da EMATER e desta organização, foi formulada a primeira lei estadual criada para assegurar o direito de produção do queijo artesanal. Em conjunto com várias entidades e associações de produtores de duas primeiras regiões, Canastra e Serro, elaboraram e produziram o dossiê para o registro do QMA como patrimônio cultural do Brasil no Instituto de Patrimônio Histórico e Artístico Nacional (IPHAN) (Shiki \& Wilkinson, 2016).

A EMATER tomou então a fundamental decisão de rebatizar o queijo Minas Frescal como Queijo Minas Artesanal, desvinculando o seu produto da legislação federal em vigor. Em 2002, a lei $N$. $^{\circ} 14.185 / 2002$ criou o QMA, o queijo de leite cru tradicional, que passou a ser um produto legal dentro do estado, sob a condição obrigatória de ter o reconhecimento e registro formal nas suas diversas regiões produtoras.

A questão central conflituosa surgiu na medida em que essas instituições adotaram, em seus registros, partes da legislação industrial com a introdução de novos conhecimentos e rotinas, muitos deles conflitando com o conhecimento tradicional. Além disso, a reestruturação da queijaria para uma conformação industrial era, e ainda é, onerosa e tem sido efetivada somente por aqueles melhor estruturados financeiramente. Alguns destes, mesmo estruturados, não chegaram a legalizar devido ao receio da fiscalização constante (Cintrão, 2016; Matos, 2016; Simoncini, 2017; Vincentini et al., 2013).

Em princípio, o que estava sendo assegurado naquele registro é de fato um processo produtivo histórico e tradicional, juntamente com partes da legislação recém-criada. A rigor, os produtores que não estão seguindo essas "partes da legislação" inscritas no Regulamento de Uso (RU) também não podem usar o sinal distintivo da IP. Essa constatação se baseia na própria regulamentação do INPI, órgão responsável pelo registro, segundo a qual somente aqueles que estariam respeitando o RU teriam o direito de usar o sinal da IP em seus rótulos, conforme a IN 25, do ano de 2013 (Melo, 2018).

De igual modo ao RU, está o Dossiê Interpretativo do QMA. Este dossiê foi montado em conjunto com o IPHAN e tem o objetivo de descrever como foi feito o reconhecimento do produto como um patrimônio imaterial. Nele, também se encontram diversos aspectos da legislação atual (Instituto do Patrimônio Histórico e Artístico Nacional, 2006).

Deste modo, o conhecimento novo da legislação do MERCOSUL trouxe uma grande alteração nesta região produtora de queijo artesanal. A adoção dos sistemas de proteção do conhecimento foi uma tentativa para assegurar o já ameaçado conhecimento do processo produtivo artesanal pela desvalorização do seu produto. Mas, conforme colocado no objetivo, se a IG trouxe uma cobertura para o conhecimento tradicional, como entender a legislação inserida nos documentos de proteção?

${ }^{3} \mathrm{Em}$ 2005, o MAPA criou uma nova secretaria que incorporou atribuições estritamente definidoras para as IG e marcas, fornecendo suporte técnico aos processos para obtenção desses registros das regiões produtoras reconhecidas (CIG, 2014). 
Para responder ao objetivo deste artigo, uma metodologia para levantar os tipos de conhecimento e as instituições envolvidas no processo de implementação da IG Canastra será detalhada na seção a seguir.

\section{METODOLOGIA DA PESQUISA}

Este artigo constrói um estudo de caso a partir de pesquisa documental e de entrevistas analisadas através da técnica de análise de conteúdo (Krippendorff, 2004). O estudo de caso é relevante no contexto da implementação das IGs, porque, nas regiões de produtos agroalimentares, há a necessidade de que a produção artesanal esteja enquadrada dentro dos parâmetros da legislação sanitária antes da IG. A inserção de dois tipos de conhecimentos exógenos à região, da legislação sanitária e da IG, delimita uma fronteira de estudo intrigante do ponto de vista acadêmico, profissional e institucional.

No sentido de Alves-Mazzotti (2006), a eleição do estudo de caso possibilita melhor compreensão e teorização do que poderá ser encontrado em outros casos de forma abrangente. No caso ora apresentado, demonstra a ação e os efeitos da assimilação dos conhecimentos exógenos no conhecimento regional.

Assim, a pesquisa que fundamentou este artigo teve como objetivo geral analisar as alterações nos fluxos de conhecimento na região da Canastra a partir da introdução da IG. Como objetivo específico, buscou-se identificar quais são os fluxos de conhecimento na região e como este afetou as relações de confiança entre os produtores.

A seção 4.1 descreve os procedimentos metodológicos utilizados na pesquisa, cujos resultados são apresentados na seção 5 deste artigo.

\subsection{Tipo de pesquisa}

Este artigo se valeu de dois tipos de pesquisa qualitativa: a pesquisa documental e a realização de entrevistas. Os documentos consultados foram uma importante fonte de dados e falam diretamente o que pensam as instituições que os produzem. A pesquisa documental realizada partiu de uma revisão bibliográfica, para, em seguida, elaborar as questões para os agentes. Dado o interesse de muitos agentes institucionais sobre o tema, foi possível dividir os agentes em grupos distintos, aplicando o questionário no grupo dos produtores e a técnica da observação participante no grupo representante das instituições. Após proceder a uma análise documental e a uma pesquisa de campo, foi possível construir o estudo de caso (Flick, 2009; Godoy, 1995).

A sequência da pesquisa se efetivou dessa forma:

1) Pesquisa bibliográfica sob a ótica delimitadora das organizações, instituições formais e informais, com base em material publicado em livros, revistas e artigos científicos, jornais, redes eletrônicas, etc.;

2) Pesquisa de campo para entender quais são os mecanismos que geram o conhecimento regional de acordo com os produtores locais e as instituições que estão assegurando sua perpetuação;

a. Os agentes foram separados em três grupos, descritos no Quadro 1. No grupo 1, foi feita observação participante; o grupo 2 respondeu a um questionário com perguntas pré-determinadas, e o grupo 3 foi entrevistado sem roteiro prédefinido.

b. As entrevistas foram gravadas e transcritas. As respostas das entrevistas dos três grupos foram introduzidas no software Atlas TI. 
Quadro 1 - Método de seleção e classificação dos Agentes e Instituições entrevistados

\begin{tabular}{|c|c|c|c|}
\hline $\begin{array}{l}\text { Grupos de } \\
\text { agentes }\end{array}$ & Grupo 1 & Grupo 2 & Grupo 3 \\
\hline Tipo de agente & $\begin{array}{l}\text { Instituições } \\
\text { externas à região: } \\
\text { Instituições } \\
\text { fomentadoras de } \\
\text { IG nacionais e } \\
\text { estaduais }\end{array}$ & $\begin{array}{c}\text { Produtores familiares, } \\
\text { cadastrados e/ou associados } \\
\text { APROCAN ou APROCAME, } \\
\text { cadastrados e não cadastrados*. }\end{array}$ & $\begin{array}{l}\text { Instituições locais, IMA, } \\
\text { EMATER, IF BAMBUÍ, } \\
\text { APROCAN, Centro de } \\
\text { Maturação de Medeiros, } \\
\text { Sindicato dos Produtores } \\
\text { Rurais, Prefeitura de Tapiraí }\end{array}$ \\
\hline $\begin{array}{l}\text { Forma do } \\
\text { questionário }\end{array}$ & $\begin{array}{l}\text { Técnica de } \\
\text { Observação } \\
\text { Participante }\end{array}$ & $\begin{array}{l}25 \text { questões abertas. A escolha } \\
\text { dos entrevistados foi realizada in } \\
\text { loco, por indicação dos próprios } \\
\text { produtores. }\end{array}$ & $\begin{array}{l}\text { Entrevistas abertas } \\
\text { realizadas in loco. Os temas } \\
\text { dessas entrevistas não } \\
\text { seguiram um roteiro pré- } \\
\text { definido, foram direcionadas } \\
\text { de acordo com o tipo de } \\
\text { conhecimento, o cargo ou a } \\
\text { função histórica dentro dos } \\
\text { acontecimentos } \\
\text { considerados relevantes pela } \\
\text { pesquisadora }\end{array}$ \\
\hline $\begin{array}{l}\text { Número de } \\
\text { respondentes }\end{array}$ & 38 respondentes & $\begin{array}{c}23 \text { respondentes das cidades de } \\
\text { Medeiros (7), Tapiraí (9), Vargem } \\
\text { Bonita (1) e São Roque de } \\
\text { Minas (6) }\end{array}$ & 9 respondentes \\
\hline $\begin{array}{l}\text { Método de } \\
\text { coleta }\end{array}$ & $\begin{array}{l}\text { Anotações pessoais } \\
\text { e perguntas } \\
\text { abertas durante } \\
\text { eventos sobre IG }\end{array}$ & $\begin{array}{l}\text { Tempo médio das entrevistas foi } \\
\text { de } 54 \text { min, com um intervalo de } \\
\text { duração entre } 15 \text { min, no } \\
\text { mínimo, e } 3 \text { horas, no máximo. } \\
\text { Foram realizadas, } \\
\text { principalmente, nas próprias } \\
\text { fazendas e, em alguns casos, na } \\
\text { "casa da cidade" do produtor. } \\
\text { Quatro visitas na cidade de São } \\
\text { Roque de Minas foram feitas } \\
\text { pela pesquisadora com } \\
\text { acompanhamento de um } \\
\text { técnico da EMATER. Quatorze } \\
\text { entrevistas foram feitas com } \\
\text { acompanhamento de algum } \\
\text { parente dos produtores. }\end{array}$ & $\begin{array}{l}\text { Tempo médio de } 40 \text { min de } \\
\text { entrevista por agente. Foram } \\
\text { realizadas durante o período } \\
\text { do campo, em idas a campo } \\
\text { na Região da Canastra ou } \\
\text { nos eventos que a } \\
\text { pesquisadora participou }\end{array}$ \\
\hline
\end{tabular}

* Certificados, cadastrados ou registrados são aqueles produtores que são registrados no IMA. Não cadastrados são produtores informais.

3) Além das entrevistas, foram coletados outros documentos relacionados à produção do QMA e IG para a pesquisa documental:

a. Dados primários: dossiê do IPHAN; Regimento Interno da APROCAN (Associação dos Produtores de Queijo Canastra, 2012); leis federais e estaduais relacionadas à proteção e à regulação da produção do QMA, e regulamentos sanitários do MERCOSUL;

b. Dados secundários: documentos de caracterização do QMA, publicações de marketing de instituições fomentadoras de IG e da produção do QMA.

Para iniciar a pesquisa de campo, foi feita uma visita exploratória em um concurso de queijos artesanais promovido pela EMATER de Belo Horizonte, quando foi possível identificar uma questão principal: a tradição e o saber fazer possuem o mesmo significado para os produtores e para as instituições? A partir da literatura apresentada e das observações desta visita, foi feito o Quadro 2, que estabelece a relação entre os tipos de conhecimentos e a sua manifestação. 
Quadro 2 - Tipos de conhecimento regional e características

\begin{tabular}{|c|c|c|c|}
\hline Tipo/ Características & Conhecimento tácito & $\begin{array}{l}\text { Conhecimento } \\
\text { formal }\end{array}$ & Tradição* \\
\hline Apresentação & Implícito & Explícito & Ambos \\
\hline O que é & Saber fazer & Processo produtivo & $\begin{array}{c}\text { Processo de } \\
\text { aprendizado falado e } \\
\text { demonstrado pelo } \\
\text { exemplo dos pais, avós. }\end{array}$ \\
\hline $\begin{array}{l}\text { Semelhança entre } \\
\text { conhecimentos }\end{array}$ & $\begin{array}{l}\text { Leve diferença individual, cada } \\
\text { um faz de um jeito. }\end{array}$ & Igual para todos. & $\begin{array}{l}\text { Leve diferença entre } \\
\text { uma fazenda e outra. }\end{array}$ \\
\hline Mecânica da mudança & $\begin{array}{l}\text { É dinâmica porque envolve } \\
\text { fatores não controláveis no } \\
\text { dia a dia, tais como clima, } \\
\text { pasto e condições físicas e } \\
\text { emocionais dos produtores. }\end{array}$ & $\begin{array}{c}\text { É estática, na medida } \\
\text { em que, para mudar, } \\
\text { deve haver primeiro a } \\
\text { mudança na } \\
\text { jurisdição. }\end{array}$ & $\begin{array}{c}\text { É dinâmica, muda com } \\
\text { o tempo, porém } \\
\text { vagarosamente. }\end{array}$ \\
\hline Laços de confiança & $\begin{array}{l}\text { As relações de confiança são } \\
\text { imprescindíveis para se } \\
\text { sustentar e para ser } \\
\text { repassado. }\end{array}$ & $\begin{array}{l}\text { Sem necessidade de } \\
\text { relação de confiança. }\end{array}$ & $\begin{array}{l}\text { Relação de confiança } \\
\text { entre filhos e netos, e } \\
\text { funcionários. }\end{array}$ \\
\hline $\begin{array}{l}\text { Conhecimento sobre } \\
\text { utensílios e meio } \\
\text { ambiente }\end{array}$ & $\begin{array}{l}\text { São incorporados ao saber } \\
\text { fazer. }\end{array}$ & $\begin{array}{l}\text { Dependente da } \\
\text { legislação. }\end{array}$ & $\begin{array}{l}\text { É dinâmico, na medida } \\
\text { em que incorpora } \\
\text { novos conhecimentos. }\end{array}$ \\
\hline Proteção & $\begin{array}{l}\text { Não há como protegê-lo sem } \\
\text { proteger aquele que o possui, } \\
\text { o próprio produtor e sua } \\
\text { família. }\end{array}$ & $\begin{array}{l}\text { É protegido no limite } \\
\text { da descrição formal. }\end{array}$ & $\begin{array}{l}\text { É protegida quando há } \\
\text { incorporação de } \\
\text { aprendizados exógenos } \\
\text { que auxiliam a prática. }\end{array}$ \\
\hline Como se protege? & Não se protege, não precisa. & $\begin{array}{l}\text { Formalmente, via } \\
\text { instituições. }\end{array}$ & $\begin{array}{l}\text { Ensinando a quem e o } \\
\text { que precisa ser } \\
\text { ensinado. }\end{array}$ \\
\hline
\end{tabular}

Referências: Berger \& Luckmann (2014), Nelson \& Winter (2012), Pesqueux (2010), Polanyi (2010), e análise da visita exploratória.

Deste quadro, foram extraídos os conceitos-chave para criação das categorias utilizadas na codificação das perguntas do Grupo 2, associados aos conhecimentos novos da legislação e da IG:

tradição, saber fazer, processo produtivo, terroir, laços de confiança, utensílios e meio ambiente, e gestão de proteção do conhecimento (associativismo, conhecimento técnico e protegido, regulamento de uso, conceitos de DO e IP)

\subsection{Codificação dos documentos ${ }^{4}$}

Foi utilizado o software Atlas TI, versão 7, que auxilia na classificação das informações e na visualização das categorias mais importantes. Este software de análise qualitativa tem capacidade de trabalhar com uma variedade significativa de tipos de documentos, incluindo vídeos, áudios e imagens, além dos textos em PDF e eletrônicos. Também auxilia nas buscas por termos e palavras-chave, possibilitando categorizar e codificar os documentos livremente pelo pesquisador ou automaticamente, feito pelo software. A utilização desse instrumento de auxílio da informática permitiu codificar todas as informações não estruturadas.

Os documentos foram inseridos na Unidade Hermenêutica $(U H)^{5}$ do Atlas TI e, para fins de organização dentro do software, os documentos foram agrupados por famílias. Todas as

\footnotetext{
${ }^{4}$ As classificações são fruto da análise de uma das autoras deste artigo a partir da leitura dos dados levantados.

${ }^{5} \mathrm{UH}$ é onde o aplicativo mostra o que é relevante no projeto. Todos os documentos digitais foram inseridos pela pesquisadora. $\mathrm{Na} U \mathrm{UH}$, é possível marcar os trechos de textos que são categorizados por códigos. Os códigos podem ser agrupados em famílias, que se referem a grupos mais ou menos homogêneos de informações.
} 
entrevistas realizadas do GRUPO 2 estão na Família Produtores; as entrevistas abertas, os documentos e relatórios, as dissertações, etc., que são originários das instituições com sede na região da Canastra, estão na Família Instituições Locais, e todas as anotações do GRUPO 1 e demais documentos e relatórios de instituições externas à região estão na Família Instituições Externas.

A vantagem no uso do Atlas TI é que o procedimento de codificação explicita os padrões que o pesquisador escolheu e minimiza os julgamentos subjetivos do processo de captação de informações durante as entrevistas (Krippendorff, 2004).

A cada pergunta do questionário do GRUPO 2, foi conferido um código, conforme o Quadro 3. Os códigos representam uma única informação que se repete nos discursos dos agentes e são representados pela sua frequência ( $\mathrm{FrC}$ ). A mesma codificação foi repetida dentro dos discursos dos produtores em outras perguntas, todas as vezes que o entrevistado repetia a mesma informação. Assim, por exemplo, o código "Tradição" apareceu tantas vezes quantas eles repetiram este conceito nas suas respostas.

Quadro 3 - Questões e códigos relacionados do questionário para os produtores

\begin{tabular}{|c|c|}
\hline Questões respondidas e classificadas & Código \\
\hline $\begin{array}{l}\text { QT } 1 \text { Há quanto tempo sua família produz queijo? Quem ensinou? De onde } \\
\text { veio a técnica? }\end{array}$ & tradição \\
\hline $\begin{array}{l}\text { QT } 2 \text { Como você explica que tantas pessoas em regiões tão distantes daqui, } \\
\text { tantos produtores conhecem o mesmo processo de fazer o queijo? }\end{array}$ & terroir \\
\hline $\begin{array}{l}\text { QT } 3 \text { Como você ensinou seu(s) filho(s)? Como você passou conhecimento } \\
\text { para eles? }\end{array}$ & Tradição \\
\hline $\begin{array}{l}\text { QT } 4 \text { Qual é a relação com seus vizinhos? Com que frequência os vê para } \\
\text { trocar ideias sobre o queijo? Já pediu ajuda para eles para resolver algum } \\
\text { problema de produção? Como foi isso? }\end{array}$ & laços de confiança \\
\hline $\begin{array}{l}\text { QT } 5 \text { Você acha que seus produtos são muito parecidos com os demais } \\
\text { associados? E com os não associados/registrados? }\end{array}$ & terroir \\
\hline QT 6 O que você entende por tradição? & tradição \\
\hline QT 6a E por saber fazer? & saber fazer \\
\hline $\begin{array}{c}\text { QT } 7 \text { Antes das modificações introduzidas pela EMATER/IMA, algum processo } \\
\text { novo foi introduzido por outra pessoa? Quem? Por quê? Você teve que } \\
\text { aprender? }\end{array}$ & legislação \\
\hline QT 8 O que você acha das normas para mudança na produção do queijo? & $/ \mathrm{NA} / *$ \\
\hline $\begin{array}{l}\text { QT } 9 \text { Quais as principais diferenças entre o Processo Produtivo anterior e o de } \\
\text { agora? }\end{array}$ & rotina e legislação \\
\hline QT 10 O que você acha que mudou e que não alterou o que você já conhece? & $\begin{array}{l}\text { tradição e } \\
\text { legislação }\end{array}$ \\
\hline $\begin{array}{l}\text { QT } 11 \text { O que você acha que não poderia ter mudado de jeito nenhum e } \\
\text { mudou por causa da legislação? }\end{array}$ & terroir e legislação \\
\hline $\begin{array}{l}\text { QT } 12 \text { O que você acha mais importante para a produção do queijo? O que, se } \\
\text { faltar, afeta no seu gosto e nas suas características? }\end{array}$ & terroir \\
\hline $\begin{array}{l}\text { QT } 13 \text { Sobre os utensílios: o material deles interfere na sua forma de fazer o } \\
\text { queijo? Se sim, em que sentido? }\end{array}$ & $\begin{array}{l}\text { utensílios, } \\
\text { estrutura e terroir }\end{array}$ \\
\hline $\begin{array}{l}\text { QT } 14 \text { O ambiente interfere na sua produção? Seu rebanho, por exemplo, seu } \\
\text { conhecimento sobre eles, afeta a maneira com que você faz o queijo? }\end{array}$ & $\begin{array}{l}\text { matéria-prima, } \\
\text { meio ambiente e } \\
\text { terroir }\end{array}$ \\
\hline QT 15 Por que você ainda não aderiu ao registro/associação? & /NA/ \\
\hline QT 16 O que você entende por IG, DO e IP? & IG \\
\hline QT 17 Por que não foi feito um trabalho para o reconhecimento pela DO? & /NA/ \\
\hline QT 18 A associação tem feito algum trabalho para atrair novos associados? & IG/APROCAN \\
\hline
\end{tabular}


Quadro 3 - Continuação...

\begin{tabular}{|c|c|}
\hline \multicolumn{1}{|c|}{ Questões respondidas e classificadas } & Código \\
\hline QT 19 Você acha que o regulamento de uso é fiel ao que você sabe fazer? & $\begin{array}{c}\text { IG/RU } \\
\text { (Regulamento de } \\
\text { Uso) }\end{array}$ \\
\hline $\begin{array}{c}\text { QT 20 Você acha que, juntando todas as informações disponíveis pelo } \\
\text { regulamento de uso, outro produtor fora da região pode aprender a fazer o } \\
\text { mesmo tipo de queijo? }\end{array}$ & $\begin{array}{c}\text { IG/RU } \\
\text { (Regulamento de } \\
\text { Uso }\end{array}$ \\
\hline QT 21 Quais as instituições que ajudam os produtores? & laços de confiança \\
\hline QT 22 Quais as que interferem demais? & laços de confiança \\
\hline
\end{tabular}

* /NA/ não analisada. Respostas em outras questões preencheram a lacuna destas perguntas. Elaboração própria.

Após esse processo, montou-se um quadro de todos os códigos, sua frequência de aparecimento e justificativas, ordenados em ordem decrescente de frequência de comparecimento nos textos das transcrições (Quadro 4).

Quadro 4 - Quadro de todos os códigos, frequência de aparecimento e justificativas, em ordem decrescente

\begin{tabular}{|c|c|c|}
\hline Nome & FrC & Observações \\
\hline Leite cru & 305 & $\begin{array}{l}\text { O termo leite cru somente foi encontrado uma vez, pois, para os produtores, } \\
\text { o leite jamais é pasteurizado. A expressão foi utilizada desta forma porque é } \\
\text { a adotada pelas entidades oficiais e legislação. }\end{array}$ \\
\hline Legislação & 290 & $\begin{array}{l}\text { Referente ao QMA, Lei N. } .^{\circ} 14.185 / 2002, \text { RT, NI, etc. } \\
\text { QT } 7 \text { a } 11 \text { e tudo o que foi citado referente a }\end{array}$ \\
\hline Tradição & 222 & QT 6 e tudo o que foi citado referente à \\
\hline Terroir & 171 & QT $2,5,11,12,13,14$ e tudo o que foi citado referente a \\
\hline Saber fazer & 148 & QT 6 ${ }^{\mathrm{a}}$ e tudo o que foi citado referente a \\
\hline IMA & 136 & \\
\hline Maturação & 132 & Tempo exigido pela lei estadual \\
\hline EMATER & 131 & \\
\hline IG & 123 & QT 16 a 20 e tudo o que foi citado referente à \\
\hline $\begin{array}{l}\text { Inovação \& } \\
\text { empreendedorismo }\end{array}$ & 115 & Inovações feitas em função da legislação \\
\hline PIQueijeiros & 115 & $\begin{array}{l}\text { Grupo de atravessadores ou queijeiros, que compram queijo nas fazendas } \\
\text { e vendem na sua própria rede de comércio. Cada queijeiro tem sua rota, } \\
\text { com certo número de produtores, e é respeitado pelos seus serviços, } \\
\text { embora sua relação com os produtores nem sempre seja positiva. É uma } \\
\text { instituição informal que partilha as mesmas práticas durante séculos, } \\
\text { recolhendo o queijo e outros bens das fazendas, e vendendo para o } \\
\text { atacadista. Ele também é responsável pela compra de utensílios domésticos } \\
\text { e de fazenda para os produtores. O código que ele aparece é Laço de } \\
\text { confiança. É interessante notar que o queijeiro não era conhecido antes da } \\
\text { pesquisa de campo. Os próprios produtores que o inseriram dentro do seu } \\
\text { contexto de trabalho. }\end{array}$ \\
\hline Mercado & 111 & Relativo a preços e mercados \\
\hline Laços de confiança & 107 & $\begin{array}{l}\text { O fato de uma instituição ser bem classificada não significa que seja de } \\
\text { confiança. Todos os códigos foram inseridos quando a instituição foi citada. } \\
\text { QT } 21 \text { e tudo o que foi citado referente a. }\end{array}$ \\
\hline APROCAN & 102 & $\begin{array}{l}\text { Quem respondeu pela instituição e por si mesmo foi seu presidente. Os } \\
\text { produtores que a compõem, por vezes, apresentaram perspectivas } \\
\text { diferentes. }\end{array}$ \\
\hline MAPA & 96 & \\
\hline
\end{tabular}


Quadro 4 - Continuação...

\begin{tabular}{|c|c|c|}
\hline Nome & FrC & Observações \\
\hline Outras UFs & 67 & $\begin{array}{l}\text { Todas as instituições de E\&P que estão trabalhando com pesquisa sobre o } \\
\text { leite cru dentro da região. }\end{array}$ \\
\hline $\begin{array}{l}\text { Centro de } \\
\text { maturação }\end{array}$ & 66 & $\begin{array}{c}\text { Centro de maturação ou de Qualidade, e fica em Medeiros. Ele só abriga } \\
\text { sete produtores e foi relevante para iniciar o processo formal de legalização } \\
\text { dos queijos para enviar para outros estados. Oficialmente, até 2014, era a } \\
\text { única instituição que possuía o selo SISBI/POA. É um projeto da EMATER e } \\
\text { do governo de Minas. }\end{array}$ \\
\hline $\begin{array}{l}\text { Conhecimento } \\
\text { Codificado }\end{array}$ & 45 & $\begin{array}{l}\text { É a descrição do conhecimento de produção artesanal do QMA que está } \\
\text { registrada tanto no Regulamento de uso quanto no IPHAN. }\end{array}$ \\
\hline SEBRAE & 32 & \\
\hline APROCAME & 27 & $\begin{array}{c}\text { É a associação vinculada ao Centro de Maturação. Somente sete produtores } \\
\text { têm acesso ao centro. Seus membros estão também associados à } \\
\text { APROCAN. }\end{array}$ \\
\hline IPHAN & 20 & \\
\hline Área demarcada & 13 & $\begin{array}{l}\text { Área delimitada pelas instituições. Regulamento de Uso e Dossiê } \\
\text { interpretativo do IPHAN. }\end{array}$ \\
\hline
\end{tabular}

Elaboração própria.

\subsection{Elaboração dos resultados do artigo}

Uma vez compiladas as frequências de utilização dos códigos, procedeu-se à interpretação dos textos dos documentos e das entrevistas tendo em vista as categorias de análise identificadas, a saber: conhecimento protegido, conhecimento tácito e conhecimento exógeno. O Quadro 4 detalha cada categoria e os códigos correspondentes.

É possível identificar se há alterações na frequência de códigos das instituições como uma medida da origem do conhecimento. A maior frequência destes denota em qual instituição há maior disseminação do conhecimento daquele código específico.

Assim, foram identificados três tipos de conhecimento extraídos dos códigos dos Grupos 1 e 2, sendo então separados em Categorias. Os códigos do conhecimento protegido foram identificados como sendo Leite cru, Legislação, Maturação, $\underline{\text { IG }}$, Pingo e Área demarcada, agrupando-os na Categoria Conhecimento Protegido (Figura 1). A Categoria Conhecimento Exógeno teve origem na introdução de conhecimentos não disponíveis na região antes da legislação e da IG (Figura 2). Os códigos relacionados a esse conhecimento são Legislação, IG Inovação e Empreendedorismo, e Área demarcada. Por fim, a Categoria Conhecimento Tácito teve origem dos códigos Leite cru, Tradição, Terroir, Saber fazer e Laços de Confiança. (Figura 3). As Figuras 1, 2 e 3 relacionam a frequência das citações dos códigos das suas respectivas categorias, em números absolutos.

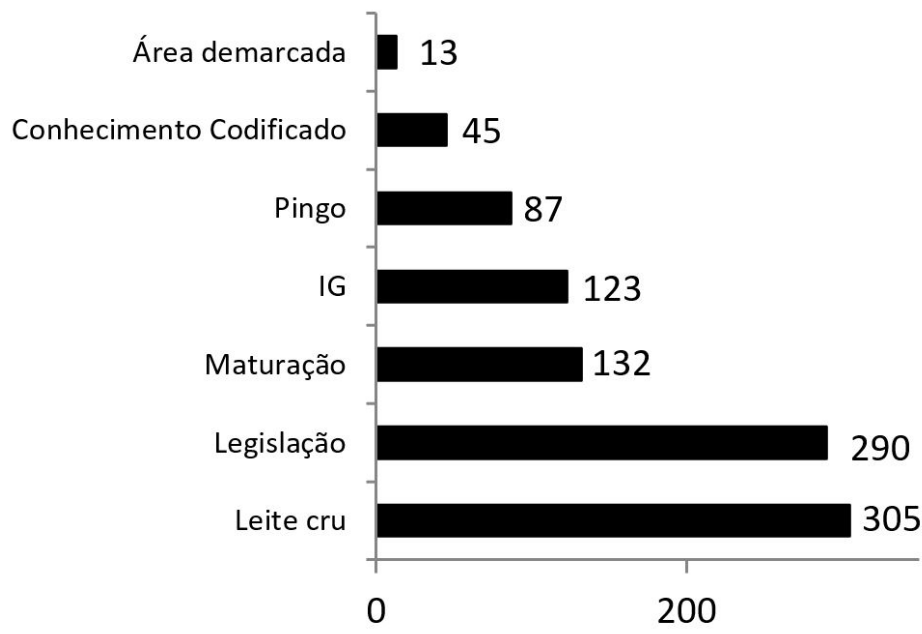

Figura 1. Frequência de citações dos códigos da Categoria Conhecimento Protegido 


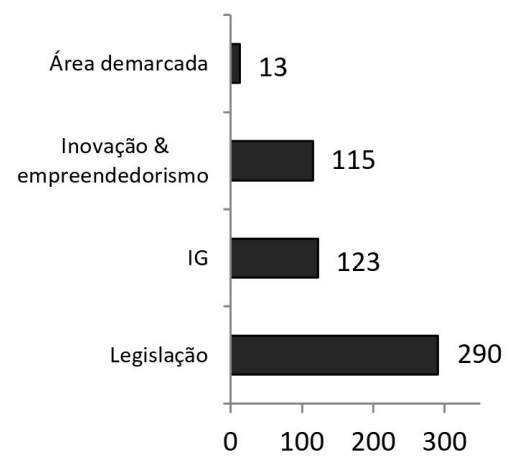

Figura 2. Frequência de citações dos códigos da Categoria Conhecimento Exógeno

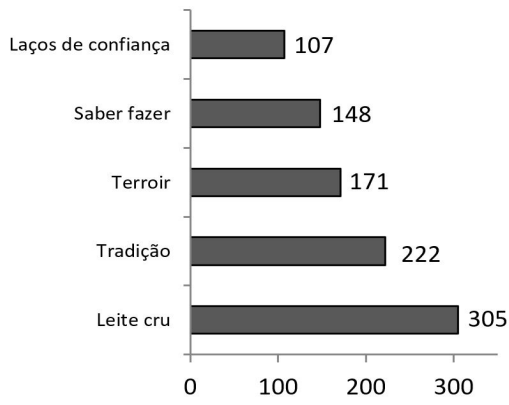

Figura 3. Frequência de citações dos códigos da Categoria Conhecimento Tácito

Os códigos da Categoria Conhecimento Protegido são referentes ao conhecimento dos documentos de proteção, do dossiê do IPHAN e do Regulamento de Uso da APROCAN. A Categoria do Conhecimento Exógeno reúne os novos conhecimentos que estão circulando na região e foram extraídos das observações dos participantes no Grupo 1, das leis federais e estaduais e suas respectivas regulamentações, bem como o regulamento sanitário do MERCOSUL. A Categoria do Conhecimento Tácito foi montada a partir da seleção dos códigos das entrevistas com os produtores.

Observa-se que há maior similaridade de códigos nas categorias dos Conhecimentos Protegido e Exógeno, em função das instituições responsáveis pela disseminação desses tipos de conhecimento.

O código Legislação, que é originalmente da categoria do conhecimento exógeno, aparece também na categoria do conhecimento protegido, porque ele consta nos documentos oficiais de proteção. Percebe-se que o conhecimento da legislação é mais citado que o conhecimento da IG, que também é exógeno.

Entre os códigos de conhecimento tácito, somente o código Leite cru aparece também na categoria do conhecimento protegido, porque ele é responsável pela característica artesanal do QMA e é o principal fator de risco dentro da legislação sanitária. Ele é a causa de a relevância do código da Legislação aparecer em segundo lugar nesta categoria e ser o primeiro na Categoria do Conhecimento Exógeno. O Leite cru é por si só uma matéria-prima exclusiva de proteção pelos órgãos responsáveis.

Foi escolhido o código da Legislação como medida de disseminação do conhecimento novo pela qual as instituições exógenas puderam influenciar o conhecimento regional.

\section{Análise dos Resultados}

No contexto de IG do QMA, é imperioso saber se tais transformações estão sendo acompanhadas pelas instituições endógenas, capazes de gerar segurança e continuidade no processo de inovação e desenvolvimento rural, ao mesmo tempo em que preserva a tradição ${ }^{6}$.

\footnotetext{
${ }^{6}$ Entende-se por instituições endógenas: IMA, EMATER, PIQUEIJEIROS e APROCAN; e por instituições exógenas, as demais.
} 
A pesquisa de campo revelou que logo após a demarcação do território, a EMATER, que já tinha uma capilaridade extensa no território mineiro, não foi convidada para participar das reuniões promovidas pelo SEBRAE, contratadas pela APROCAN (Matos, 2016).

Mesmo que se trate de diferentes vocações institucionais, dado que tanto a legislação como os registros de proteção servem para todos os produtores que estão dentro da região, a disseminação desses novos conhecimentos depende dos laços de confiança estabelecidos ex ante.

A pesquisa de Ruffoni et al. (2017) corrobora esta afirmação demonstrando que a proximidade geográfica apresenta forte característica de relações horizontais estabelecidas pelas empresas e instituições locais: "o conhecimento tecnológico que circula no local é essencialmente trocado com firmas e instituições do próprio território" (Ruffoni et al., 2017, p. 585).

Binotto et al. (2013) também encontraram que a socialização é um meio de troca de conhecimento tácito ordinariamente utilizado pelos produtores rurais para se manterem informados sobre seu mercado. Para além dos parentes próximos, nos momentos de encontros sociais, tais como as missas ou cultos, ou em reuniões de organizações endógenas ou escolas, relacionadas ou não à produção, são fortalecidos os laços de confiança, as trocas de ideias e as experiências. Acrescenta-se que eles têm o hábito de fazer avaliações de comportamento dos indivíduos antes que haja qualquer abertura para troca de conhecimentos. Esses comportamentos são tácitos e, portanto, construídos com o tempo.

Isso implica afirmar que, se o conhecimento circula e é relevante de acordo com suas origens e pelo seu poder de transmissão, a disseminação das informações relacionadas à IG e à legislação depende do alcance e do poder das instituições envolvidas. Assim, mesmo que as instituições exógenas sejam as oficialmente encarregadas pela transmissão do conhecimento, são as instituições endógenas que o validam.

As Figuras 4 e 5 a seguir demonstram que os novos conhecimentos (Legislação e IG) têm influências distintas sobre os tipos de conhecimento e que o conhecimento da IG é, de fato, dependente do conhecimento da legislação.

Essas figuras demonstram também os códigos por instituição comparando os tipos de conhecimento regional encontrados com a modificação da inserção do código da legislação como um novo conhecimento. O posicionamento entre as instituições se desloca de acordo com seu maior envolvimento com este código. Desta forma, fica evidente que as instituições também assimilam um novo conhecimento, além daqueles que já dominam.

As figuras demonstram ainda as alterações ocorridas na Categoria Conhecimento Protegido com a inserção do código da legislação. A posição da APROCAN e da EMATER (Figura 5) passa a ter menos relevância que o MAPA. A instituição PIQueijeiros não altera sua posição, apontando que os queijeiros e suas práticas não foram afetados pela legislação.

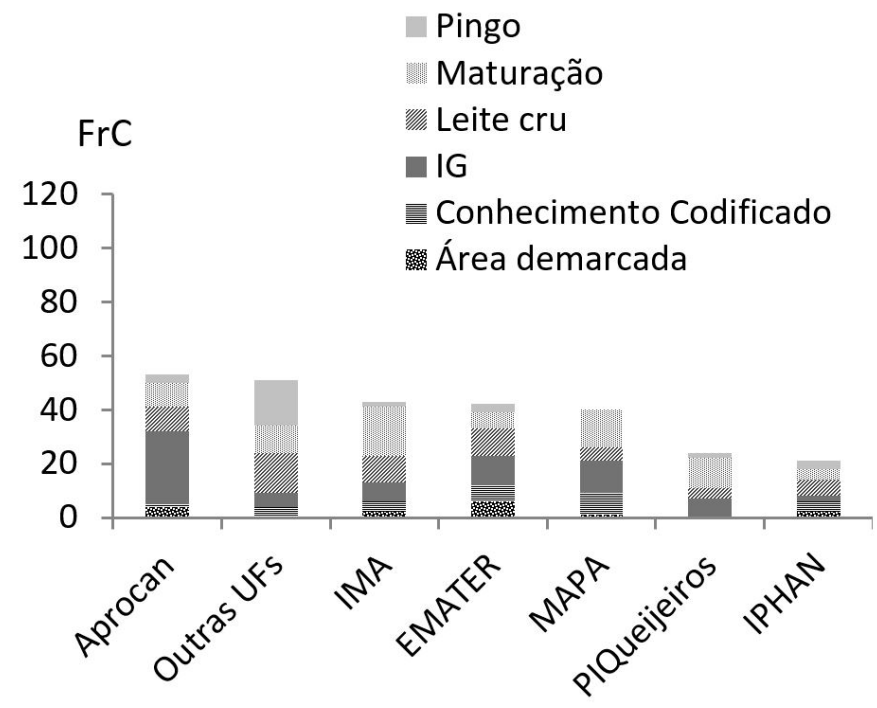

Figura 4. As 7 instituições com maior frequência de códigos da Categoria do Conhecimento Protegido 


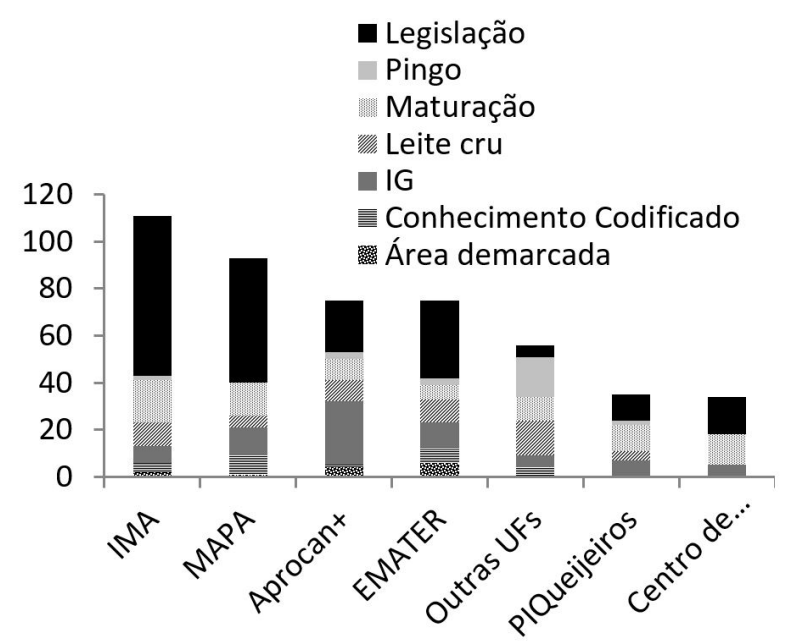

Figura 5. As 7 instituições com maior frequência de códigos da Categoria Conhecimento Protegido e código Legislação

Esta alteração demonstra que o conhecimento protegido é afetado muito mais pela legislação do que pelos outros tipos de conhecimento relacionados à IG. Se a APROCAN pudesse se ater somente às questões da IG, ela poderia ter mais influência na região.

Nas Figuras 6 e 7, a frequência dos códigos da Categoria Conhecimento Exógeno com e sem o código da legislação demonstra que há também uma modificação na ordem de instituições que mais citam códigos, devido à variação entre elas. A legislação diminui a importância da IP como conhecimento novo e altera a integração das instituições dentro da região. Instituições com forte relação com este código têm maior influência do que aquelas que não a possuem.

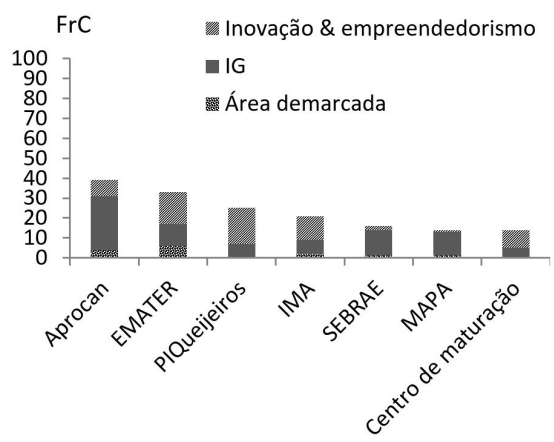

Figura 6. As 7 instituições com maior frequência de códigos da Categoria Conhecimento Exógeno

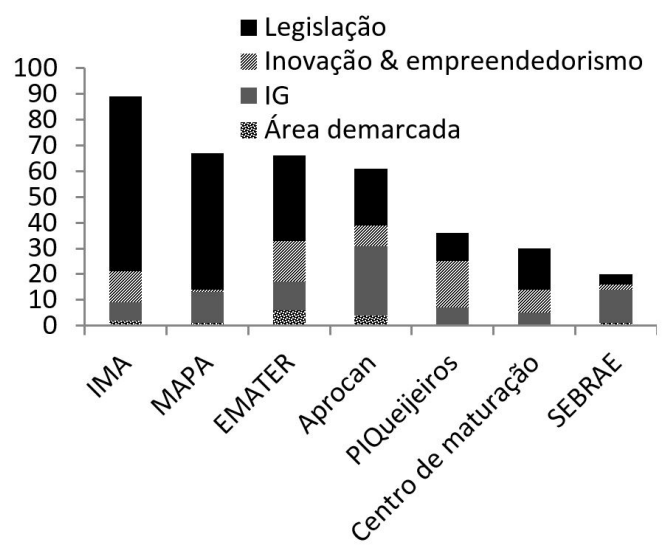

Figura 7. As 7 instituições com maior frequência de códigos da Categoria Conhecimento Exógeno e do código Legislação 
Pode-se observar também que a EMATER muda sua posição quando o código legislação é introduzido por esta ser uma instituição sem atividade proeminente no processo da IG, quando os códigos estão correlacionados somente com os elementos do terroir e dos laços de confiança. Isso também ocorre com o SEBRAE, que perde posições quando se introduz 0 código legislação. Ressalta-se o objetivo primordial de IG desta última instituição. O MAPA aparece em sexto lugar na Figura 6, mas, quando se insere a legislação, sobe para o segundo lugar (Figura 7). O SEBRAE, ao contrário, aparece com pouca expressividade com o código de IG e menos ainda com o código área demarcada.

As Figuras 8 e 9 demonstram as instituições que mais citaram os códigos da Categoria Conhecimento Tácito sem e com o código legislação, respectivamente. A percepção de que os produtores - formais ou não, associados ou não - incorporaram partes da legislação em seu conhecimento tácito fica clara pela alteração na ordem das instituições, quando o código da legislação é inserido. Desta forma, a Figura 9 demonstra que as instituições locais apresentam maior vínculo com essa categoria, enquanto que a legislação provoca uma reordenação das instituições com menor vínculo endógeno.

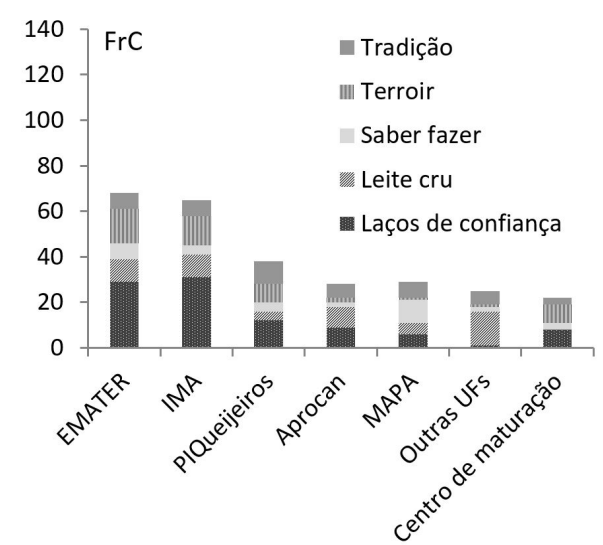

Figura 8. As 7 instituições com maior frequência de códigos da Categoria Conhecimento Tácito

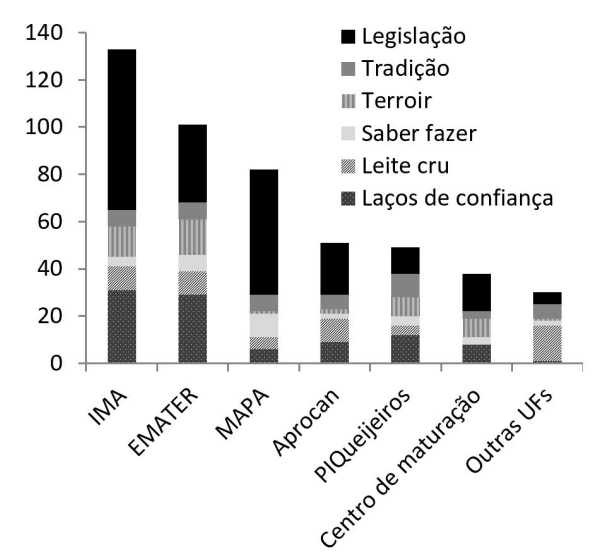

Figura 9. As 7 instituições com maior frequência de códigos da Categoria Conhecimento Tácito e do código Legislação

Na Categoria Conhecimento Tácito, o código Laços de Confiança possui importante expressão nas instituições endógenas e pouca expressão nas instituições exógenas. A instituição PIQueijeiros muda sua posição na lista das instituições com maior frequência de códigos quando se insere o código da legislação. Tal acontecimento se explica pela ausência dessa instituição informal nas ações do estado de Minas Gerais e pela falta de interesse da APROCAN em buscar esses profissionais (Matos, 2016). Percebe-se que a posição da APROCAN não sofre modificações, porque já foi criada dentro das estruturas de conformação da legislação, segundo o Regulamento de Uso. 
A importância da legislação sobre o conhecimento tácito demonstra que não só ela foi incorporada como também é mais representativa do que todos os outros códigos juntos. Em função disso, o MAPA apresenta muita representatividade, porque dele emanam a legislação e o controle da fiscalização, bem como a vigilância sanitária.

Alguns pontos importantes devem ser destacados:

1) Ao analisar as frequências das famílias dos três tipos de conhecimento, percebe-se que o conhecimento tácito tem mais representatividade do que os demais, devido à sua relação direta com os produtores;

2) O deslocamento das instituições demonstrado nas figuras revela que a busca pelo conhecimento da legislação do QMA por parte dos produtores, mesmo que adotada em parte, aproxima as instituições que dominam esse tipo de conhecimento, aumentando sua relevância na região, como é o caso do MAPA e do IMA. Ao mesmo tempo, afasta aquelas que não o possuem, como é o caso do PIQueijeiros. Também implica em afirmar que a legislação tem afetado o conhecimento regional;

3) O conhecimento da legislação tem sido mais disseminado do que os demais conhecimentos sobre IG;

4) O conhecimento da legislação está sendo protegido [não somente] pelas instituições de proteção, IPHAN e INPI, mas também pelas demais instituições formais.

\section{CONSIDERAÇÕES FINAIS}

O objetivo do presente trabalho foi levantar os tipos de conhecimento encontrados na IP Canastra depois da inserção de novas rotinas da legislação e da IP, além de verificar se o conhecimento novo trazido pelas instituições exógenas afetou as relações de confiança entre os produtores e as instituições endógenas e exógenas. Foram identificados três tipos de conhecimento: o conhecimento protegido, que se refere aos parâmetros para a criação e implementação da IP na região; o conhecimento tácito, que se refere à transmissão de conhecimento pela tradição e tem por premissa básica as relações de confiança, e o conhecimento exógeno, que se refere ao novo conhecimento trazido pelas instituições exógenas através da legislação.

Em relação aos impactos do novo conhecimento trazido pelas instituições endógenas e exógenas, encontrou-se que a legislação sanitária teve fundamental influência sobre o conhecimento regional, por causa dos documentos oficiais de proteção, a saber o Regulamento de Uso (RU) e o dossiê interpretativo do IPHAN. O IMA e o MAPA são as principais transmissoras e mantenedoras deste conhecimento.

Já o conhecimento tácito se encontra fortalecido nas instituições endógenas, EMATER e IMA, principalmente. Com a introdução da legislação como conhecimento novo, o IMA passa a ter maior representatividade na sua transmissão. Por fim, as duas fontes da transmissão do conhecimento exógeno são, primordialmente, o IMA e o MAPA.

Pelos resultados encontrados, é possível entender que, graças aos laços de confiança estabelecidos anteriormente pelo IMA e pela EMATER, o conhecimento da legislação pode ser introduzido eficazmente pelo alcance destas instituições locais na região, tanto entre os produtores formais quanto informais. Esses achados vão na mesma direção dos resultados de Ruffoni et al. (2017) e Binotto et al. (2013).

Este resultado difere do que ocorreu com o conhecimento da IG, que tem a APROCAN como principal fonte de disseminação. Esta instituição é relativamente nova e tem poucos associados. Simoncini (2017) encontrou somente 41 associados à APROCAN, em 2016, em uma região com mais de 1.700 produtores do QMA. Os laços de confiança entre produtores e essa instituição são ainda frágeis, dependentes da percepção dos ganhos monetários em relação ao investimento necessário para se associar. Nem o IMA nem a EMATER tiveram qualquer atuação na disseminação do conhecimento da IG. Resultados similares sobre o papel do IMA e da EMATER na IG foram encontrados em Cintrão (2016). 
Respondendo à primeira pergunta formulada na seção 2, em função da flexibilidade da tradição produtiva dos produtores, houve a agregação parcial do conhecimento da legislação ao modo produtivo artesanal, respeitando a pureza da sua principal matéria-prima, o leite cru.

Em resposta para a segunda pergunta, pode-se afirmar que, mesmo tendo sido a legislação incorporada aos mecanismos de proteção, nenhuma instituição pode garantir que o conhecimento regional esteja protegido formalmente. Um exemplo disso é a norma de maturação de 21 dias, especificada nos dois documentos de proteção do QMA, que não é respeitada pela maior parte dos produtores, formais ou não.

As inovações produtivas e organizacionais implementadas na produção do QMA foram voltadas para o atendimento às exigências da legislação de normas sanitárias. Contudo, preservar o caráter original do conhecimento tradicional no produto significaria dar aos produtores condições de desenvolver inovações ligadas à cultura da região, o que não ocorre no caso analisado. As rotinas da legislação enquadraram o processo produtivo dentro de um limitado padrão e sair dele significa cair na ilegalidade.

Como demonstrado, o entendimento da influência das instituições endógenas na disseminação de conhecimento novo torna-se primordial para auxiliar as implementações de novas IGs. Políticas públicas voltadas para IGs poderiam ser mais assertivas se conseguissem consolidar as relações de confiança entre as instituições exógenas e endógenas. Esta ação se tornaria eficaz instrumento de desenvolvimento regional.

\section{BIBLIOGRAFIA}

Alves-Mazzotti, A. J. (2006). Usos e abusos dos estudos de caso. Cadernos de Pesquisa, 36(129), 637-651.

Associação dos Produtores de Queijo Canastra - APROCAN. (2012). Regulamento de uso. São Roque de Minas: APROCAN.

Berger, P. L., \& Luckmann, T. (2014). A construção social da realidade: tratado de sociologia do conhecimento (36. ed.). Petrópolis: Vozes.

Binotto, E., Nakayama, M. K., \& Siqueira, E. S. (2013). A criação de conhecimento para a gestão de propriedades rurais no Brasil e na Austrália. Revista de Economia e Sociologia Rural, 51(4), 681-698. http://dx.doi.org/10.1590/S0103-20032013000400004.

Britto, J. (2004). Cooperação e aprendizado em arranjos produtivos locais: em busca de um referencial analítico. Rio de Janeiro: Rede de Pesquisa em Sistemas Produtivos e Inovativos Locais - IE/UFRJ.

Capello, R. (2013). Science-based activities in European regions: the knowledge-innovation nexus. In R. Capello, A. Olechnicka \& G. Gorzelak. Universities, cities and regions: loci for knowledge and innovation creation. London: Routledge.

Cerdan, C. M. T., Bruch, K. L., Silva, A. L., Copetti, M., Fávero, K. C., \& Locatelli, L. (2014). Indicação Geográfica de produtos agropecuários: importância histórica e atual. Florianópolis: EAD/UFSC/FAPEU.

CIG. (2014). Valorizando origem, qualidade e tradição: o papel do mapa no incentivo ao uso dos signos distintivos (pp. 1-20). Ilhéus: CIG. Slides.

Cintrão, R. P. (2016). Segurança, qualidade e riscos: a regulação sanitária e os processos de (i)legalização dos queijos artesanais de leite cru em Minas Gerais (Tese de doutorado). Universidade Federal Rural do Rio de Janeiro, Instituto de Ciências Humanas e Sociais, Rio de Janeiro.

Cooke, P., De Laurentis, C., Tödtling, F., \& Trippl, M. (2007). Regional knowledge economies: markets, clusters and innovation. Cheltenham: Edward Elgar.

Diniz, C. C. (2013). Dinâmica regional e ordenamento do território brasileiro: desafios e oportunidades. Belo Horizonte: Cedeplar, Universidade Federal de Minas Gerais.

Erber, F. (2008). Eficiência coletiva em arranjos produtivos locais: comentando o conceito. Nova Economia, 18(1), 11-32.

Flick, U. (2009). Introdução à pesquisa qualitativa (3. ed.). Porto Alegre: Artmed editora.

Godoy, A. S. (1995). Pesquisa qualitativa: tipos fundamentais. Revista de Administração de Empresas, 35(3), 20-29.

Gonçalves, E., Lemos, M. B., \& Negri, J. A. (2011). The role of firm and territory in innovative activities in Brazilian post-opening economy. Economia Aplicada, 15(1), 103-130.

Hodgson, G. M. (2014). Conceptualizing capitalism (pp. 1-355). Hertfordshire, UK: University of Hertfordshire. 
Institut National de L'origine et de la Qualité - INAO. (2015). Guide du demandeur d'une appellation d'origine protégée (AOP) ou d'une indication géographique protégée (IGP) à l'exception des vins et des boissons spiritueuses. Montreuil-sous-Bois, France: INAO.

Instituto do Patrimônio Histórico e Artístico Nacional - IPHAN. (2006). Queijo Artesanal de Minas: patrimônio cultural do Brasil: Dossiê Interpretativo (Vol 1. Belo Horizonte: Ministério da Cultura Instituto do Patrimônio Histórico e Artístico Nacional - IPHAN Inventário Nacional de Referências Culturais - INRC). Belo Horizonte: IPHAN. Recuperado em 14 de janeiro de 2016, de http://portal.iphan.gov.br/uploads/ckfinder/arquivos/Dossie_modo_fazer_queijo_minas.pdf

Krippendorff, K. (2004). Content analysis: an introduction to its methodology. London: Sage publications.

Matos, L. A. I. (2016). O conhecimento regional do queijo Minas artesanal na indicação de procedência Canastra: ensinando o padre a rezar (Tese de doutorado). Instituto de Economia, Programa de Pós-graduação em Políticas Públicas, Estratégias e Desenvolvimento, Universidade Federal do Rio de Janeiro, Rio de Janeiro.

Matos, L. A. I., Ximenes, A. C. A., \& La Rovere, R. L. (2015). Institutions and knowledge diffusion in a territory: the case of geographical indications. In Proceedings of the 2nd WINIR Conference - Institutions, Development and Globalization (Vol. 1). London: WINIR.

Mafra, L. A. S. (2010). Gestão do patrimônio imaterial: reflexões sobre os direitos de propriedades nas indicações geográficas. Revista Pós Ciências Sociais, 7(13), 65-82.

Melo, R. D. (2018). Os critérios de concessão e uso de indicações geográficas sob a ótica do direito da regulação e da concorrência (Tese de doutorado). Academia de Inovação e Propriedade Intelectual do Instituto Nacional da Propriedade Industrial - INPI, Rio de Janeiro.

Mercosul. (1996). Regulamento Técnico Mercosul de Identidade e Qualidade do Queijo Minas Frescal. MERCOSUL/GMC/RES/No. 145/96. Recuperado em 14 de janeiro de 2016, de http://www.mercosur.int/innovaportal/v/3093/2/innova.front/resoluciones1996.\%20Acesso\%20em\%2007\%20jan\%202016

Nelson, R. R., \& Winter, S. G. (2012). Uma teoria evolucionária da mudança econômica. Campinas: Editora UNICAMP.

Niederle, P. A., Wilkinson, J., \& Mascarenhas, G. C. C. (2016). Introdução, In J. Wilkinson, P. A. Niederle \& G. Mascarenhas. O sabor da origem (pp. 257-316). Porto Alegre: Escritos.

Perez, R. (2014). Cadastro georreferenciado dos produtores de queijo minas artesanal da região da Serra da Canastra (54 p). Belo Horizonte: SICOOB - Saromcredi, SEBRAE/MG; São Roque de Minas: APROCAN.

Pesqueux, Y. (2010). De la référence à la tradition au regard de l'innovation (pp. 16). Recuperado em 18 de abril de 2014, de http://halshs.archives-ouvertes.fr/hal-00509702/

Polanyi, M. (2010). A dimensão tácita. Lisboa, Portugal: MIT Portugal Inovatec.

Ribeiro, J. C., \& Santos, J. F. (2008). Portuguese quality wine and the region-of-origin effect consumers and retailers' perceptions. Braga: NIPE - Núcleo de Investigação em Políticas Econômicas.

Ruffoni, J., Tatsch, A. L., Stefani, R., Schaeffer, P. R., \& Grings, L. G. (2017). Does the geographical proximity matter in knowledge and information flow? A studyaboutwine cluster in the Southern region of Brazil. Revista de Economia e Sociologia Rural, 55(3), 569-588. http://dx.doi.org/10.1590/1234-56781806-94790550309.

Shiki, S. F. N., \& Wilkinson, J. (2016). Movimentos em torno dos queijos artesanais de origem: os casos da Canastra e do Serro, In J. Wilkinson, P. A. Niederle \& G. Mascarenhas. O sabor da origem (pp. 257-316). Porto Alegre: Escritos.

Simoncini, J. B. V. B. (2017). Produzir para viver ou viver para produzir: conflitos vividos pelos produtores familiares e as estratégias de resistência no território do queijo Canastra (Tese de doutorado). Universidade Federal de Santa Maria, Programa de Pós-graduação em Geografia, Santa Maria.

Valente, M. E. R., Perez, R., \& Fernandes, L. R. R. M. V. (2013). O processo de reconhecimento das indicações geográficas de alimentos e bebidas brasileiras: regulamento de uso, delimitação da área e diferenciação do produto. Ciência Rural, 43(7), 1330-1336. http://dx.doi.org/10.1590/S0103-84782013005000076.

Vincentini, N. M., Carneiro, A. V., Mendonça, L. C., \& Brito, M. A. V. P. (2013). Custo da adequação de pequenos produtores de queijos aos requisitos da legislação do estado de Minas Gerais. Revista do Instituto de Latícinios Cândido Tostes, 68(395), 5-14.

Submetido: 1/Dez./2017.

Aceito: 6/Out./2019

Classificação JEL: A14, Q18 